\title{
Focal fibrocartilaginous dysplasia (FFCD) in the proximal femur causing coxa vara: A unique case report and review of the literature
}

\author{
Dr PH Maré MBChB, FCOrth(SA) \\ Dr DM Thompson MBChB, FCS(Glasgow) \\ Correspondence: \\ Dr PH Maré \\ PO Box 351 \\ 3231 Msunduzi \\ Tel: +2733 8973050 \\ Cell: +27832948375 \\ Email:phmare@gmail.com
}

Grey's Hospital, Nelson R Mandela School of Medicine, University of KwaZulu-Natal

\begin{abstract}
Background: Focal fibrocartilaginous dysplasia (FFCD) is an uncommon developmental defect of bone, where cortical bone is replaced by fibrous tissue. The condition has most commonly been reported in the upper tibia causing tibia vara. Several other sites have also been described including the distal femur, ulna, humerus, radius and phalanx.

Methods: We report a unique case of FFCD of the upper medial femur that caused coxa vara. The diagnosis was suspected on X-ray and confirmed on MRI and histology. Treatment included valgus subtrochanteric proximal femoral osteotomy, intralesional biopsy and curettage of the lesion. A literature review using PubMed/Medline and Google Scholar was completed to identify previous publications on FFCD up to February 2015.

Results: This is the first report of FFCD associated with coxa vara in the proximal femur. Eighteen cases of FFCD in the distal femur have previously been reported. The disorder is most commonly reported in the proximal tibia.

Conclusion: FFCD should be considered in the differential diagnosis of a cortically based lytic lesion associated with bony deformity in growing bone. Further research is needed to define the aetiopathogenesis and natural history of the disorder. Treatment guidelines are needed for atypical locations.
\end{abstract}

Level of evidence: Level V (case report)

Key words: focal fibrocartilaginous dysplasia (FFCD), proximal femur, coxa vara

http:/ /dx.doi.org/10.17159/2309-8309/2016/v15n3a8

\section{Introduction}

Focal fibrocartilaginous dysplasia (FFCD) is a rare developmental cause of unilateral angular deformity in long bones in childhood. ${ }^{1}$ A well-defined, cortical lesion that appears lytic on X-ray causes the deformity. The aetiology remains unclear and the natural history is poorly understood.

The disorder is most commonly recorded in the medial cortex of the proximal tibia and is associated with tibia vara. It has also been reported at several other sites. These include the distal femur, ulna, humerus, radius and phalanx, but never before in the proximal femur.

We report a unique case where FFCD in the posteromedial proximal femur was associated with coxa vara.

\section{Materials and methods}

Informed consent was obtained from the patient's parent for a case report and publication in a peer-reviewed journal. The patient's clinical and radiological data were retrieved and reviewed. A literature review using PubMed/Medline and Google Scholar was completed to identify previous publications on FFCD up to February 2015.

\section{Case report}

A 5-year-old girl child presented to our unit with a progressive, painless limp that was noticed at the start of walking (age 1 year). There was no relevant family history and no history of trauma. 


\section{Examination}

Examination revealed a healthy child who was active and fit. She walked with a Trendelenburg gait associated with an increased, mobile lumbar lordosis and pelvic obliquity. Palpation revealed a high riding trochanter. Abduction was limited to 10 degrees. All other movements of the hip were normal. Shortening of $2.5 \mathrm{~cm}$ was noted in the right leg confined to the supratrochanteric region.

\section{X-ray}

Pre-operative radiographs (Figure 1) confirmed a located hip with coxa vara. This was associated with an isolated lucent lesion in the medial cortex of the right proximal femur with surrounding sclerosis and cortical thickening extending distally. The site of lesion corresponded with the insertion of the psoas tendon. The neck-shaft angle measured $87^{\circ}$ and the Hilgenreiner-epiphyseal angle $86^{\circ}$.

\section{Blood investigations}

Blood investigations included full blood count, erythrocyte sedimentation rate, C-reactive protein, urea and electrolytes, HIV testing, calcium, magnesium and phosphate and alkaline phosphatase. These were within normal limits.

\section{MRI}

The lesion in the medial neck correlated with the lesion seen on X-ray and showed hypo-intensity on T1W (Figure 2) and proton density (PD) (Figure 3) views. Minimal STIR hyperintensity was seen surrounded the area of sclerosis (Figure 4). A small amount of fluid was seen in the iliopsoas bursa with inclusion of tendon in the area of abnormal signal in the medial neck of the femur (Figure 5). Coxa vara was confirmed. There was no evidence of avascular necrosis or slip of the femoral head. MRI concluded that FFCD was the likely diagnosis.

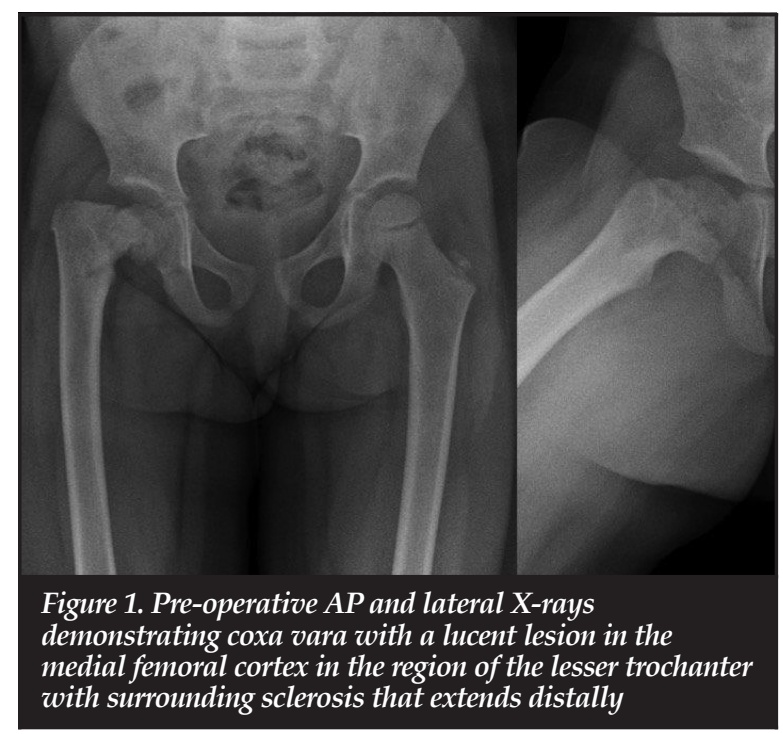

\section{Management}

Observation for 6 months showed no improvement. A valgus osteotomy of the proximal femur was performed together with percutaneous adductor tenotomy. An incisional biopsy with curettage was taken. Stable fixation was achieved with a 130 degree paediatric LCP hip plate (Synthes GmBH Eimattstrasse $3 \mathrm{CH}-4436$ Oberdorff).
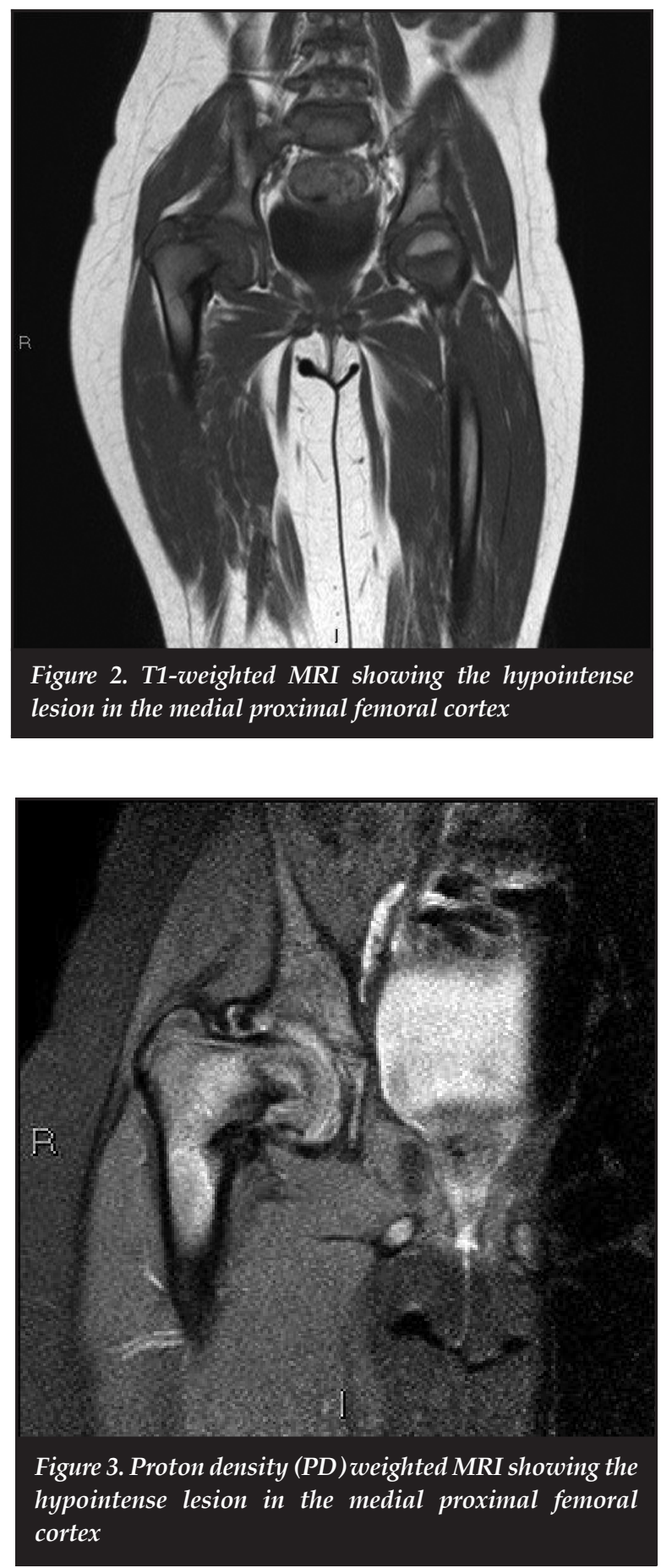


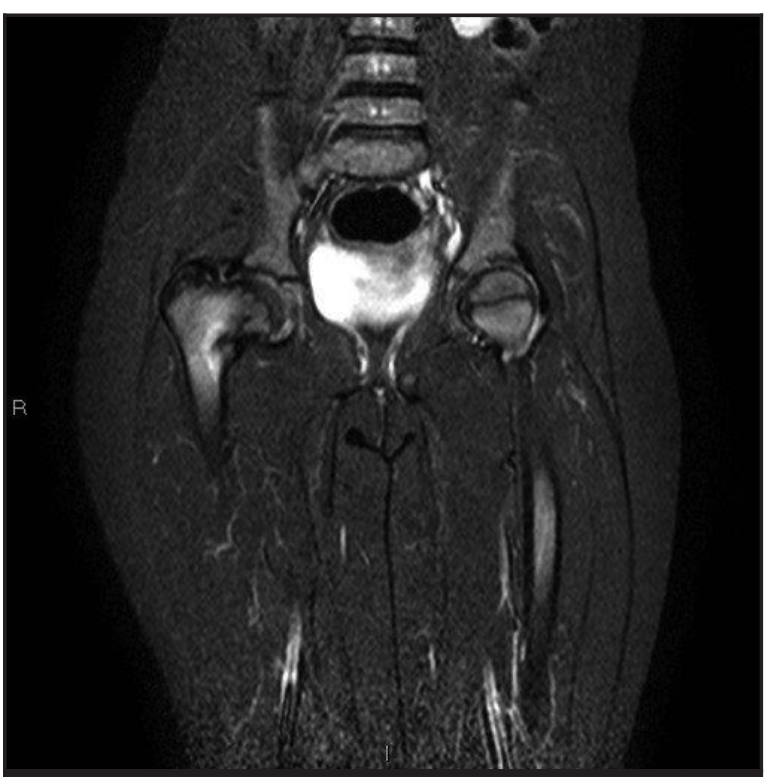

Figure 4. Short tau inversion recovery (STIR) MRI showing the hypointense image with an area of minimal hyperintensity surrounding it

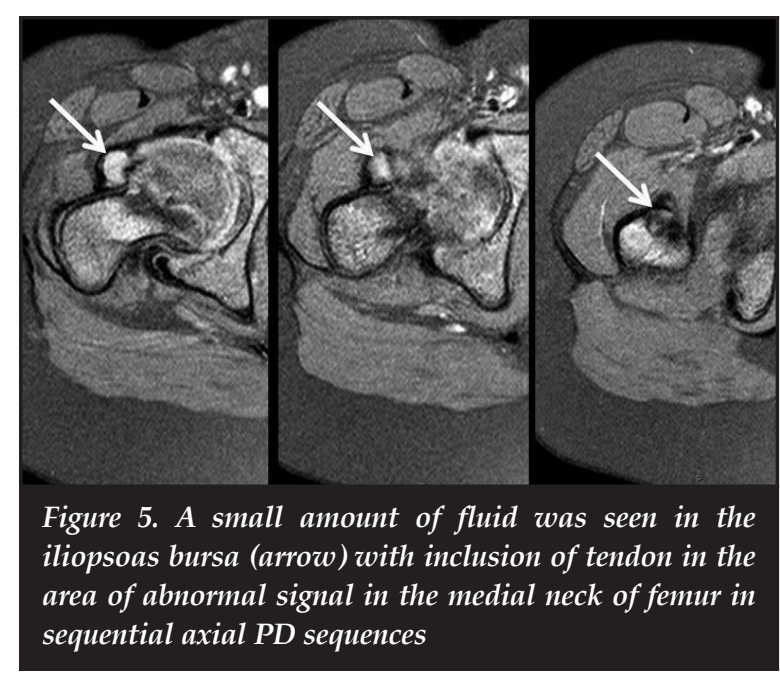

\section{Pathology}

Histological evaluation of specimens stained with haematoxylin and eosin revealed dense fibrous tissue, fibrocartilage and bone (Figure 6) Areas of pale, hyalinised fibrocartilage were also present. These findings support a diagnosis of FFCD. ${ }^{1-3}$

The child made an uneventful recovery with union achieved and leg length restored to within $1 \mathrm{~cm}$ of the contralateral side. Follow-up X-rays at 8 months (Figure 7) demonstrated resolution of the lesion with metal-ware in situ. The neck-shaft angle was corrected to $120^{\circ}$ (opposite side $145^{\circ}$ ) and the Hilgenreiner-epiphyseal angle measured $45^{\circ}$. Follow-up at 18 months showed maintenance of correction with complete resolution of the lesion.
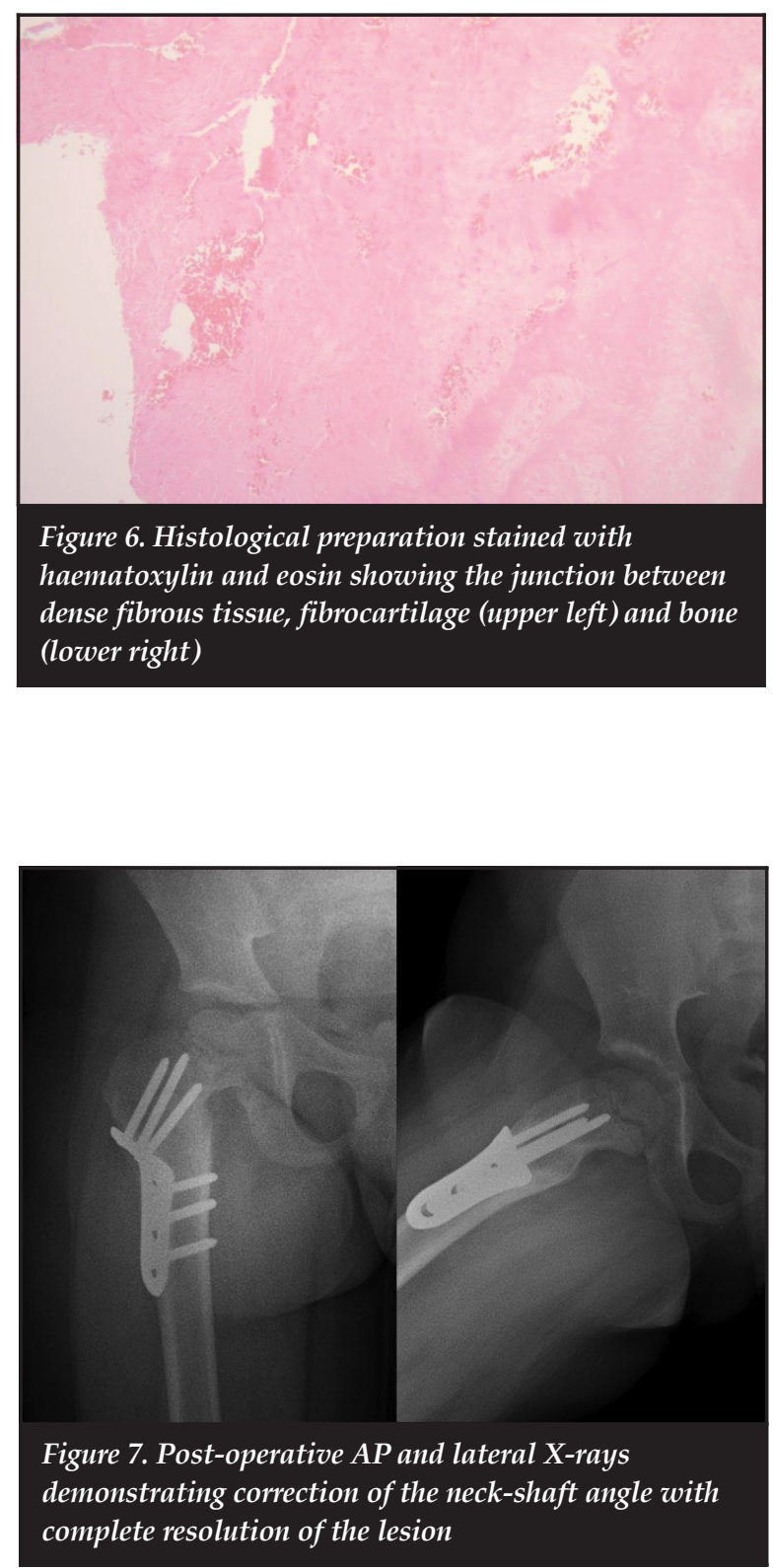

\section{Discussion}

The disorder was first described as a cause of tibia vara in three cases by Bell et al. ${ }^{1}$ in 1985 . Onset of deformity is generally early and a literature review shows the average age at presentation to be 24 months. Lesions in the lower limb were diagnosed earlier (91 cases; average 18 months) than upper limb lesions (22 cases; average 47 months). Children present with unilateral, painless limb bowing. Associated features may include mild shortening and rotation.

Since Bell's initial description, 110 additional patients with the condition have been reported in the literature. It has been most commonly recorded in the medial cortex of the proximal tibia and associated with tibia vara (68 cases). ${ }^{1,-22}$ 
Three cases of a lateral tibial lesion causing tibial valgus have also been reported. ${ }^{16,23,24}$ It has also been reported at several other sites. This includes the distal femur (18 cases), ${ }^{25-31}$ ulna (16 cases), ${ }^{3,32-36}$ humerus (four cases), ${ }^{32,37}$ radius (two cases) ${ }^{33}$ and phalanx (two cases), ${ }^{33}$ but never in the proximal femur.

The typical radiological appearance of FFCD is a welldefined, lytic lesion situated in the cortex of a long bone with surrounding sclerosis. ${ }^{19,20}$ Sclerosis and cortical thickening extend distally in proximal lesions and proximally in distal lesions. ${ }^{3}$ It does not involve the physis. The lesion is associated with bowing of the long bone.

Magnetic image resonance images typically show a lesion that is cortically based which is hypo-intense on T1W images and does not show increased uptake of contrast. $^{12}$

Histology reveals a variety of findings: from dense, fibrous and tendon-like tissue to benign fibrocartilaginous tissue. ${ }^{2,3}$ Individual specimens show regional variation in cellularity with dense fibrous areas being pauci-cellular and more cellular areas of fibrocartilage. Areas of hyalinised fibrocartilage have also been described. . $^{2,3}$ Prominent areas of osteoblastic and osteoclastic activity in and around some lesions support the theory of active remodelling. Kim et al. ${ }^{2}$ suggest, after analysing specimens from the femur and the tibia, that this variation represents a transition from fibrocartilage to dense fibrous tissue during the evolution of the disorder.

Bell et al. ${ }^{1}$ first described the aetiopathogenesis. They postulate that abnormal mesenchymal differentiation at the site of insertion of the pes anserine is responsible for disordered growth on the medial aspect of the proximal tibia. In our case MRI demonstrated inclusion of the psoas tendon insertion within the lesion. In our estimation this corresponds to the abnormal insertion of the pes anserine in the proximal tibia, supporting the abnormal periosteal anchor aetiological theory. Jouve et al. ${ }^{19}$ describe the effect of the abnormal insertion of the pes anserine in the proximal tibia further. They believe the entity represents an abnormal anchor of the pes anserine causing an 'epiphyseodesis-like' effect on the adjacent physis. For this reason they prefer the term 'fibrous periosteal inclusion'. Other authors describe non-anatomical fibrous bands inserted in a subperiosteal cortical defect to be associated with angular deformities. ${ }^{19,2435,36}$ Choi et al. ${ }^{3}$ and Poul and Straka ${ }^{16}$ describe an isolated subperiosteal fibrous cortical inclusion without any abnormal tendon or fibrous band in their cases. We agree with Jouve et al. ${ }^{19}$ that an abnormal periosteal anchor causes an epiphyseodesis-like effect during growth and resultant angular deformity. They also postulate that smaller lesions may rupture spontaneously, resulting in deformity correction. Larger lesions may persist, causing progressive deformity. These lesions would likely require surgical correction.

The natural history is variable depending on the site of the lesion. Spontaneous resolution of FFCD of the tibia vara was first reported by Bell et al. ${ }^{1}$ in one of their three cases, and Dusabe et al. ${ }^{17}$ reported that a varus deformity of the tibia of up to 30 degrees should correct spontaneously. Choi et al. ${ }^{3}$ report that up to $45 \%$ of tibial lesions are likely to undergo spontaneous recovery. Initial treatment should be observation, ${ }^{1,3,19}$ with surgery indicated in progressive or biomechanically and cosmetically unacceptable lesions. ${ }^{19}$

Most femoral lesions were found to be progressive and reported treatment has mostly included deformity correction with osteotomies. Later reports indicate that timeous curettage and/or fibrous band excision (or hemicircumferential periosteal release) may prevent the need for osteotomy. ${ }^{13,16,29}$ There is only one case report of a femoral lesion spontaneously correcting (over a 7-year period). ${ }^{31}$

In the upper limb the most common site described is the ulna. Ulnar bowing in these cases may be associated with radial head dislocation, and early treatment is advised to prevent this complication. ${ }^{19}$ Four cases in the proximal humerus have been described to be progressive without spontaneous correction. ${ }^{32,37}$

Our case had a typical clinical presentation, except for the proximal femoral location of the lesion, which corresponded with the insertion of the psoas tendon. The differential diagnosis is described in Table I. Coxa vara is bilateral in skeletal dysplasia. Proximal focal femoral deficiency (PFFD) and congenital short femur have significant associated shortening. The absence of a Fairbank's triangle excludes developmental coxa vara. There is no osteopaenia nor a lytic lesion as seen in 'soft bone' conditions such as osteogenesis imperfecta, rickets and fibrous dysplasia. There was no history of trauma. Cortical lesions such as fibrous cortical defect, osteoid osteoma and periosteal chondroma were excluded clinically, radiologically and histologically. We propose that FFCD be added as an acquired cause due to a pathological bone condition.

\begin{tabular}{|c|c|c|}
\hline \multirow{3}{*}{ Congenital } & \multicolumn{2}{|c|}{ Proximal focal femoral deficiency (PFFD) } \\
\hline & \multirow{2}{*}{$\begin{array}{l}\text { Skeletal } \\
\text { dysplasia }\end{array}$} & Cleidocranial dysplasia \\
\hline & & Metaphyseal dysplasia \\
\hline \multirow{11}{*}{ Acquired } & \multirow{6}{*}{$\begin{array}{l}\text { Pathological } \\
\text { bone } \\
\text { conditions }\end{array}$} & Fibrous dysplasia \\
\hline & & Osteogenesis imperfecta \\
\hline & & Rickets \\
\hline & & Renal osteodystrophy \\
\hline & & Focal fibrocartilaginous dysplasia (FFCD) \\
\hline & & Other bone softening conditions \\
\hline & \multirow{5}{*}{$\begin{array}{l}\text { Other } \\
\text { conditions }\end{array}$} & Slipped Capital Femoral Epiphysis (SCFE) \\
\hline & & Legg-Calvé-Perthe's disease \\
\hline & & Post-traumatic \\
\hline & & Post-infective \\
\hline & & Following reduction of DDH \\
\hline Developmental & \multicolumn{2}{|c|}{ Developmental coxa vara } \\
\hline
\end{tabular}


In the proximal tibia clinical appearance and radiography should be adequate for a diagnosis of FFCD, with MRI used only for doubtful cases. ${ }^{20}$ In our case (due to the atypical location) radiographs alone were inadequate for a diagnosis. MRI was considered mandatory, while the biopsy confirmed the diagnosis.

A clear history of a deterioration of limp with persistent deformity (coxa vara) under observation for 6 months were our indications for surgery. We cannot state whether spontaneous correction is likely to occur with a FFCD in the proximal femur, but we treated this patient on clinical and radiological grounds, as for any child with a coxa vara deformity.

\section{Conclusion}

This is the first report of focal fibrocartilaginous dysplasia in the proximal femur. FFCD should be considered in the differential diagnosis of a cortically based lytic lesion associated with bony deformity in growing bone. Further research is needed to define the aetiopathogenesis and natural history of the disorder. Treatment guidelines are needed for atypical locations.

\section{Compliance with Ethics Guidelines}

Drs PH Maré and DM Thompson have no conflict of interest to declare.

The content of the article is the original work of the authors. No benefits of any form have been or are to be received from a commercial party related directly or indirectly to the subject of the article.

Informed consent was obtained from the patient's parent for a case report and publication in a peer-reviewed journal.

\section{References}

1. Bell SN, Campbell PE, Cole WG, Menelaus MB. Tibia vara caused by focal fibrocartilaginous dysplasia. Three case reports. J Bone Joint Surg (Br) 1985 Nov;67(5):780-84.

2. Kim CJ, Choi IH, Cho TJ, Chung CY, Chi JG. The histological spectrum of subperiosteal fibrocartilaginous pseudotumor of long bone (focal fibrocartilaginous dysplasia). Pathol Int 1999 Nov;49(11):1000-1006.

3. Choi IH, Kim CJ, Cho TJ, Chung CY, Song KS, Hwang JK, et al. Focal fibrocartilaginous dysplasia of long bones: report of eight additional cases and literature review. J Pediatr Orthop 2000 Jul-Aug;20(4):421-27.

4. Bradish CF, Davies SJ, Malone M. Tibia vara due to focal fibrocartilaginous dysplasia. The natural history. J Bone Joint Surg (Br) 1988 Jan;70(1):106-108.

5. Husien AM, Kale VR. Tibia vara caused by focal fibrocartilaginous dysplasia. Clin Radiol 1989 Jan;40(1):104-105.

6. Herman TE, Siegel MJ, McAlister WH. Focal fibrocartilaginous dysplasia associated with tibia vara. Radiology 1990 Dec;177(3):767-68.

7. Olney BW, Cole WG, Menelaus MB. Three additional cases of focal fibrocartilaginous dysplasia causing tibia vara. J Pediatr Orthop 1990 May-Jun;10(3):405-407.
8. Kariya Y, Taniguchi K, Yagisawa H, Ooi Y. Focal fibrocartilaginous dysplasia: consideration of healing process. $J$ Pediatr Orthop 1991 Jul-Aug;11(4):545-47.

9. Landreau-Jolivet I, Pilliard D, Taussig G. [Unilateral tibia vara in young children caused by focal fibrocartilaginous dysplasia. Apropos of 4 new cases]. Rev Chir Orthop Reparatrice Appar Mot 1992;78(6):411-14.

10. Zayer M. Tibia vara in focal fibrocartilaginous dysplasia. A report of 2 cases. Acta Orthop Scand 1992 Jun;63(3):353-55.

11. Cockshott WP, Martin R, Friedman L, Yuen M. Focal fibrocartilaginous dysplasia and tibia vara: a case report. Skeletal Radiol 1994 Jul;23(5):333-35.

12. Meyer JS, Davidson RS, Hubbard AM, Conard KA. MRI of focal fibrocartilaginous dysplasia. J Pediatr Orthop 1995 May-Jun;15(3):304-306.

13. Albinana J, Cuervo M, Certucha JA, Gonzalez-Mediero I, Abril JC. Five additional cases of local fibrocartilaginous dysplasia. J Pediatr Orthop Part B 1997 Jan;6(1):52-55.

14. Khanna G, Sundaram M, El-Khoury GY, Merkel K. Focal fibrocartilaginous dysplasia: curettage as an alternative to conservative management or more radical surgery. Skeletal Radiol 2001 Jul;30(7):418-21.

15. Postovsky S, Militianu D, Bialik V, Vlodavsky E, Elhasid $\mathrm{R}$, Peled $\mathrm{M}$, et al. Concomitant focal fibrocartilaginous dysplasia of the tibia and eosinophilic granuloma of the jaw in a child. J Pediatr Orthop Part B 2002 Apr;11(2): $172-75$.

16. Poul J, Straka M. [Periosteal tethering of growth plates in long bones (focal fibrocartilaginous dysplasia)]. Acta Chir Orthop et Traumatol Cech 2003;70(3):182-86.

17. Dusabe JP, Docquier PL, Mousny M, Rombouts JJ. Focal fibrocartilaginous dysplasia of the tibia: long-term evolution. Acta Orthop Belg 2006 Jan;72(1):77-82.

18. Bakman M, Monu JU. Focal fibrocartilaginous dysplasia (FFCD). Pediatr Radiol 2007 Jan;37(1):107.

19. Jouve JL, Kohler R, Mubarak SJ, Nelson SC, Dohin B, Bollini G. Focal fibrocartilaginous dysplasia ('fibrous periosteal inclusion'): an additional series of eleven cases and literature review. I Pediatric Orthop 2007 JanFeb;27(1):75-84.

20. Ringe KI, Schirg E, Rosenthal H, Berendonk H, Galanski M. Unilateral tibia vara in a toddler caused by focal fibrocartilaginous dysplasia. J Radiol Case Rep 2009;3(9):14-17.

21. Jibri Z, Chakraverty J, Thomas P, Kamath S. Focal fibrocartilaginous dysplasia and spontaneously resolving bowing of the leg. J Pediatr 2013 Nov;163(5):1527 e1.

22. Pavone V, Testa G, Riccioli M, Sessa A, Evola FR, Avondo $\mathrm{S}$. The natural history of focal fibrocartilaginous dysplasia in the young child with tibia vara. Eur J Orthop Surg Traumatol 2014 May;24(4):579-86.

23. Santos M, Valente E, Almada A, Neves J. Tibia valga due to focal fibrocartilaginous dysplasia: case report. J Pediatr Orthop Part B 2002 Apr;11(2):167-71.

24. Mooney JF, Slone HS. Two unusual presentations of focal fibrocartilaginous dysplasia. J Pediatr Orthop Part B 2013 Jul;22(4):367-71.

25. Beaty JH, Barrett IR. Unilateral angular deformity of the distal end of the femur secondary to a focal fibrous tether. A report of four cases. J Bone Joint Surg (Am) 1989 Mar;71(3):440-45. 
26. Vallcanera Calatayud A, Sanguesa Nebot C, Martinez Fernandez M, Cortina Orts H. Varus deformity of the distal end of the femur secondary to a focal fibrous lesion. Pediatr Radiol 1994;24(1):74-75.

27. Amillo S, Mora G, Leniz P. Progressive genu valgum secondary to a fibrous tether at the distal aspect of the femur. A case report. J Bone Joint Surg (Am) 1998 Mar;80(3):424-27.

28. Macnicol MF. Focal fibrocartilaginous dysplasia of the femur. J Pediatr Orthop Part B 1999 Jan;8(1):61-63.

29. Ruchelsman DE, Madan SS, Feldman DS. Genu valgum secondary to focal fibrocartilaginous dysplasia of the distal femur. J Pediatr Orthop 2004 Jul-Aug;24(4):408-13.

30. Ando A, Hatori M, Hosaka M, Hagiwara Y, Kita A, Ochiai $\mathrm{T}$, et al. A patient with focal fibrocartilaginous dysplasia in the distal femur and review of the literature. The Tohoku journal of experimental medicine. 2008 Aug;215(4):307-12.

31. Thabet AM, Belthur MV, Herzenberg JE. Spontaneous resolution of angular deformity of the distal femur in focal fibrocartilaginous dysplasia: a case report. J Pediatr Orthop Part B 2010 Mar;19(2):161-63.

32. Lincoln TL, Birch JG. Focal fibrocartilaginous dysplasia in the upper extremity. J Pediatric Orthop 1997 JulAug;17(4):528-32.
33. Smith NC, Carter PR, Ezaki M. Focal fibrocartilaginous dysplasia in the upper limb: seven additional cases. $J$ Pediatric Orthop 2004 Nov-Dec;24(6):700-705.

34. Kazuki K, Hiroshima K, Kawahara K. Ulnar focal cortical indentation: a previously unrecognised form of ulnar dysplasia. J Bone Joint Surg (Br) 2005 Apr;87(4):540-43.

35. Gottschalk HP, Light TR, Smith P. Focal fibrocartilaginous dysplasia in the ulna: report on 3 cases. J Hand Surg 2012 Nov;37(11):2300-3003.

36. Verhoeven N, De Smet L. Focal fibrocartilaginous dysplasia in the upper limb: case report and review of the literature. J Genet Couns 2013;24(4):373-79.

37. Eren A, Cakar M, Erol B, Ozkurt A, Guven M. Focal fibrocartilaginous dysplasia in the humerus. J Pediatr Orthop Part B 2006 Nov;15(6):449-52.

This article is also available online on the SAOA website (www.saoa.org.za) and the SciELO website (www.scielo.org.za). Follow the directions on the Contents page of this journal to access it. 